\title{
Influenza surveillance in the Islamic Republic of Iran from 1991 to 2001
}

T. Mokhtari-Azad, ${ }^{1}$ H. Mohammadi, ${ }^{1}$ A. Moosavi, ${ }^{1}$ Z. Saadatmand ${ }^{1}$ and R. Nategh ${ }^{1}$

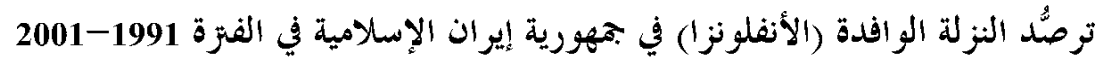

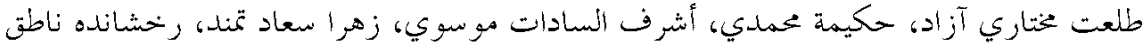

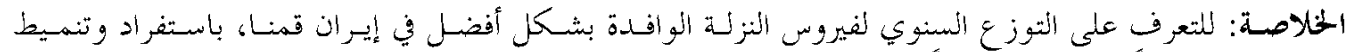

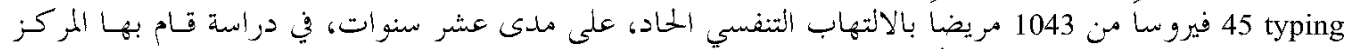

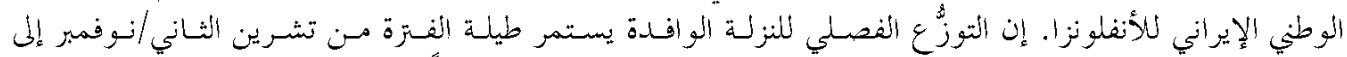

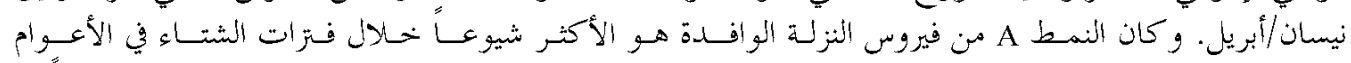

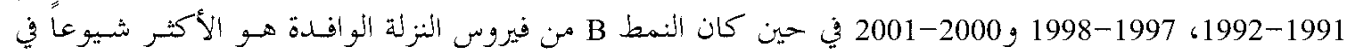

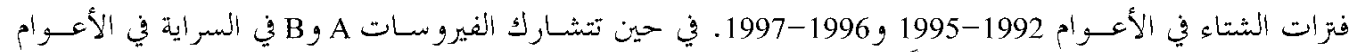

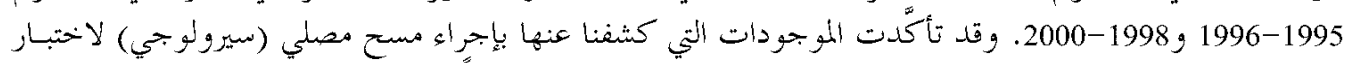

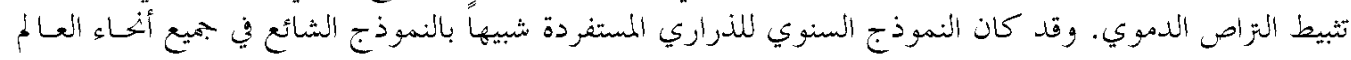

$$
\text { في الفترة المدروسة. }
$$

ABSTRACT To better understand the annual distribution of influenza virus in our country, we isolated and typed 45 viruses from 1043 patients with acute respiratory illnesses in a 10-year study conducted by the National Influenza Centre of the Islamic Republic of Iran The seasonal distribution of influenza typically ran from November to April. Type A influenza was most common during the winters of 1991-92, 1997-98 and 2000-01 and type B influenza was most common during 1992-5 and 1996-97. Both type A and type B viruses circulated in 1995-96 and 1998-2000. A serological survey based on haemagglutination inhibition test confirmed our findings. The annual pattern of strains isolated was similar to the worldwide pattern during the same interval.

\section{Surveillance de la grippe en République islamique d'Iran de 1991 à 2001}

RESUME Afin de mieux comprendre la distribution annuelle du virus de la grippe dans notre pays, nous avons procédé à l'isolement et au typage de 45 virus provenant de 1043 patients atteints de maladies respiratoires aiguës au cours d'une étude sur 10 ans réalisée par le Centre national de la grippe en Iran. La distribution saisonnière de la grippe s'étendait généralement de novembre à avril. La grippe de type $A$ était plus courante pendant les hivers des années 1991-1992, 1997-1998 et 2000-2001 et la grippe de type B était plus courante durant les années 1992-1995 et 1996-1997. Les virus grippaux A et B circulaient en 19951996 et 1998-2000. Une enquête sérologique basée sur le test d'inhibition de l'hémagglutination a confirmé nos résultats. Le profil annuel des souches isolées était similaire au profil mondial pendant le même intervalle de temps.

${ }^{1}$ Department of Virology, School of Public Health and Institute of Public Health Research, Tehran University of Medical Sciences, Tehran, Islamic Republic of Iran.

Received: 14/11/2001; accepted 27/06/2002

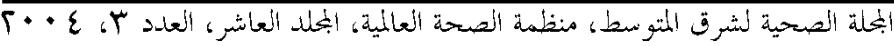




\section{Introduction}

Infection with influenza viruses results in a spectrum of clinical responses ranging from asymptomatic infection to viral pneumonia that can rapidly progress to a fatal outcome [1]. A typical, uncomplicated influenza syndrome is tracheobronchitis with the additional involvement of small airways [2]. Influenza viruses have a major impact on morbidity in hospitalizations. Morbidity has recently been defined in children, in women of all ages with high-risk conditions and in pregnant women [3-5].

Influenza remains an important virological infection that can cause epidemics or pandemics following the emergence of new strains due to drift or shift in viral surface antigens $[1,6]$. To monitor prevalent strains, the World Health Organization (WHO) maintains a collaborative surveillance network with reference laboratories.

The National Influenza Centre of the Islamic Republic of Iran at the School of Public Health, Tehran University of Medical Sciences, Tehran records the distribution of influenza viruses every year. This includes the isolation and typing of influenza viruses and the estimation of population antibody levels by haemagglutination inhibition (HI) testing against particular strains of influenza viruses in particular years.

The seasonal distribution of influenza in the country is typically from November to April with a peak number of cases recorded in February (Figure 1). To better understand the annual distribution of influenza virus in the country, we conducted virological and serological investigations over a 10-year period beginning with the 1991-92 influenza season and ending in the 2000-01 season.

\section{Methods}

Pharyngeal washing and throat swabs from 1043 patients with acute respiratory illness were collected from patients attending clinics in Tehran and from patients in the other provinces (sent to us by the Ministry of Health). These patients had fever, cough, sore throat, general malaise, chills and myalgia. The samples were transported from collection points to our laboratory according to WHO protocols. Viruses were isolated by amniotic and allantoic inoculation into 10-11-day-old embryonated chicken eggs

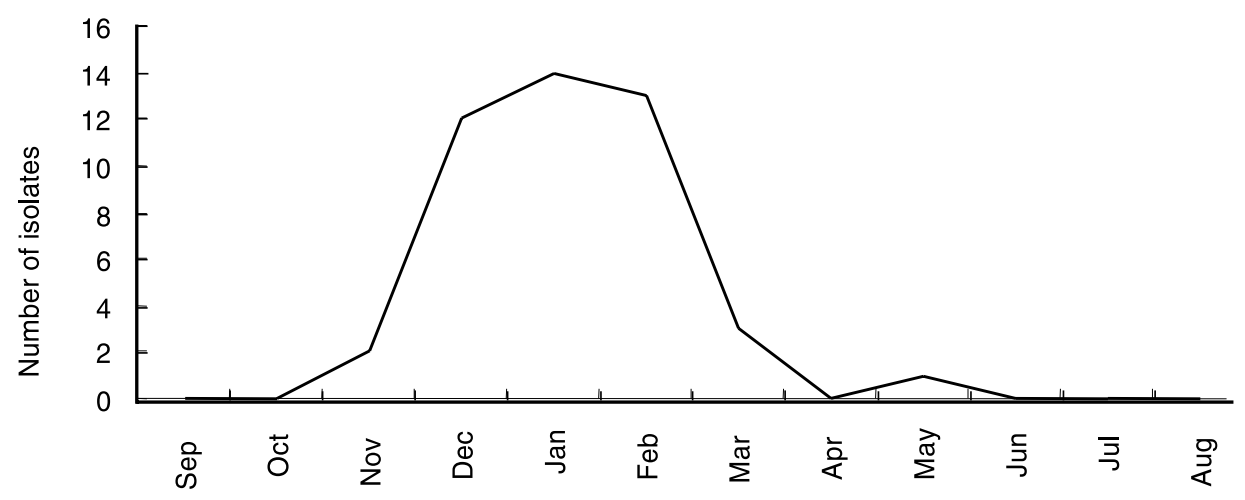

Figure 1 Distribution of influenza isolated by month over the period 1991 to 2001

البحلة الصحية لشرق المتونط، منظمة الصحة العالمية، ابخلد العاشر، العلدد ب، ع • •؟ 
and then typed by HI test following WHO protocols [3]. Prototype strains of viruses and antisera were provided by the WHO Collaborating Centre, London, United Kingdom. All viruses were sent to the WHO influenza centres in London or Sydney for further typing and sequencing.

During 1991-2001, a total of 4973 serum samples were collected from among all age groups. Standard microtitre techniques $(0.5 \%$ hen erythrocytes, 4 units of viruses) were used to detect serum $\mathrm{HI}$ antibodies at the dilutions from 1:10 to $\geq 1: 640$. Unspecific inhibitors were removed by treatment with receptor-destroying enzyme or potassium periodate [3]. The HI antibodies were determined by different strains of influenza A (H1N1), A (H3N2) and B antigens that were prepared from viruses circulating during the particular season.

\section{Results}

Figure 1 shows the results of isolation and typing of viruses during 1991-2001. Of 1043 throat samples, 45 influenza viruses were isolated and typed. Most of the isolations were made in winter (Figure 1). Influenza viruses were isolated every year during the 10-year period. Type A (H3N2) viruses were isolated in the winters of 1991-92 and 1997-98. Type B viruses were isolated in the winters of 1992-93, 1993-94, 1994-95 and 1996-97. Both type A (H3N2) and type B viruses were circulating in the winters of 1995-96, 1998-99 and 1999-2000. During the 10-year period influenza type $\mathrm{A}(\mathrm{H} 1 \mathrm{~N} 1)$ was isolated only in the winter of 2000-2001. Table 1 shows our national data and WHO international data.

Figures 2 and 3 show the results of the serological survey. The percentages of an- tibody titre (titre $\geq 40$ ) against influenza type $\mathrm{A}$ and $\mathrm{B}$ differed during the 10-year period (Figure 2). A greater than 4-fold increase in antibody titre (titre $\geq 1: 160$ ) indicated recent infection, suggesting that in recent years both influenza type $\mathrm{A}$ and $\mathrm{B}$ were circulating, whereas in past years type A was more common (Figure 3).

\section{Discussion}

During 1991-2001, the influenza viruses circulating in the Islamic Republic of Iran displayed patterns identical to those seen worldwide (Table 1) [8-17].

Influenza viruses were isolated from all age groups. High fever, chill and myalgia were the predominant signs and symptoms of these patients.

In the winter of 1991-92, the percentage of antibody titre $\geq 1: 40$ against influenza type B was $3.2 \%$. For the next 5 years, only influenza type $B$ was isolated with the level of HI antibody to type B influenza gradually increasing and reaching its highest level in the winter of 1994-95 (92.0\%).

Interpretation of prevalence on the basis of laboratory confirmation was difficult due to potential inadequacies in specimen handling, the transit time of the specimens, and the capacity of the laboratory. In the Islamic Republic of Iran, the absence of data on morbidity and mortality from pneumonia makes interpretation even more difficult.

During the 10-year study period, influenza type A (H3N2) was isolated in 199192, in 1995-96 and in each of the influenza seasons during the years 1997-2000. However, according to seroepidemiological data, influenza type B was also circulating during this time. Influenza type A (H1N1) was isolated in the winter of 2000-01 (Ta-

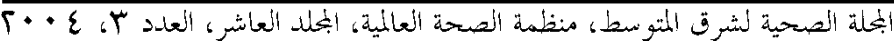




\begin{tabular}{|c|c|c|c|}
\hline \multirow{2}{*}{$\begin{array}{l}\begin{array}{l}\text { Influenza } \\
\text { season }\end{array} \\
1991-92\end{array}$} & \multirow{2}{*}{$\begin{array}{c}\text { Strains isolated in Islamic } \\
\text { Republic of Iran }\end{array}$} & \multicolumn{2}{|c|}{ Strains isolated worldwide } \\
\hline & & A/Washington/15/91 (H3N2) & B/Panama/45/90 \\
\hline & & A/Texas/36/91 (H1N1) & B/Quingdao/102/91 \\
\hline \multirow[t]{2}{*}{ 1992-93 } & B/Panama/45/90 & A/Beijing/32/92 (H3N2) & B/Panama/45/90 \\
\hline & & A/Texas/36/91 (H1N1) & B/Quingdao/102/91 \\
\hline \multirow[t]{2}{*}{ 1993-94 } & B/Panama/45/90 & A/Shangdong/9/93 (H3N2) & B/Panama/45/90 \\
\hline & & & B/Quingdao/102/91 \\
\hline \multirow[t]{3}{*}{ 1994-95 } & B/Panama/45/90 & A/Johanesburg/33/94 & B/Beijing/184/93 \\
\hline & & A/Singapore/6/80 (H1N1) & B/Shanghai/4/94 \\
\hline & & A/Texas/36/91 (H1N1) & \\
\hline \multirow[t]{3}{*}{ 1995-96 } & B/Panama/45/90 & A/Wuhan/359/95 (H3N2) & B/Beijing/184/93 \\
\hline & $A^{a}$ & A/Singapore/6/80 (H1N1) & B/Harbin/7/94 \\
\hline & & A/Texas/36/9 (H1N1) & \\
\hline \multirow[t]{3}{*}{$1996-97$} & B/Beijing/184/93 & A/Wuhan/359/95 (H3N2) & B/Beijing/184/93 \\
\hline & & & B/Harbin/7/94 \\
\hline & & & B/Guangdong/5/94 \\
\hline \multirow[t]{3}{*}{ 1997-98 } & A/Nanchang/933/95 (H3N2) & A/Wuhan/359/95 (H3N2) & B/Beijing/184/93 \\
\hline & & & B/Harbin/7/94 \\
\hline & & & B/Victoria/2/87 \\
\hline \multirow[t]{2}{*}{ 1998-99 } & A/Sydney/05/97 (H3N2) & A/Sydney/5/97 & B/Beijing/184/93 \\
\hline & B/Beijing/184/93 & A/Wuhan/359/95 & B/Beijing/243/97 \\
\hline \multirow[t]{2}{*}{ 1999-00 } & A/Sydney/05/97 (H3N2) & A/Moscow/10/99 (H3N2) & B/Beijing/184/93 \\
\hline & B/Yamanashi & A/Beijing/262/95 (H1N1) & \\
\hline \multirow[t]{3}{*}{ 2000-01 } & A/New Caledonia/20/99 & A/Moscow/10/99 & B/Sichuan/379/99 \\
\hline & & A/Panama/2007/99 & \\
\hline & & A/New Caledonia/20/99 & \\
\hline
\end{tabular}

aTyping of virus using immunofluorescence test.

ble 1). The presence of $\mathrm{HI}$ antibody with titre $\geq 160$ confirmed the circulation of both type A and type B (Figure 3).

Although it was not a common practice to isolate influenza type $\mathrm{C}$ (because of its mild symptoms), for the first time in this laboratory we performed a serum survey on influenza type C. We found that $43.7 \%$ of the samples contained antibody titre $\geq 1: 40$ against this type with the pattern of seropositivity distribution in different age groups similar to that seen in other countries [18]. 


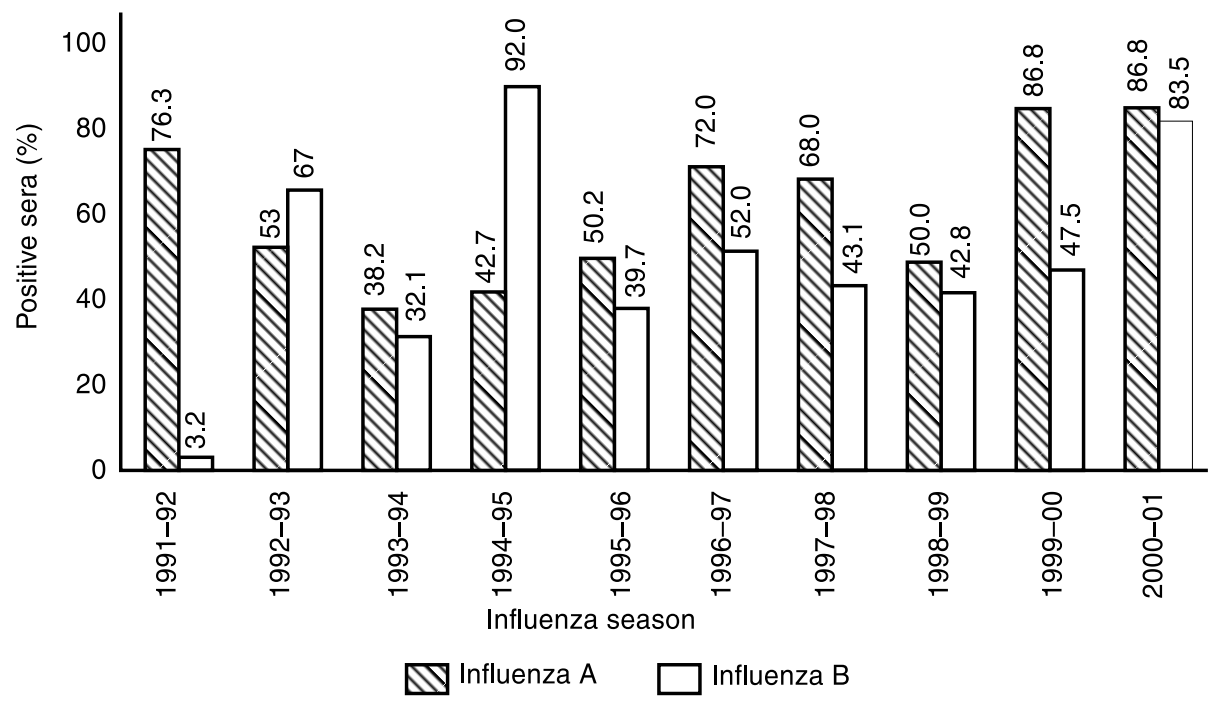

Figure 2 Seroepidemiology of influenza A and B during 1991-2001 (positive sera = HI antibody titre $\geq 40$ )

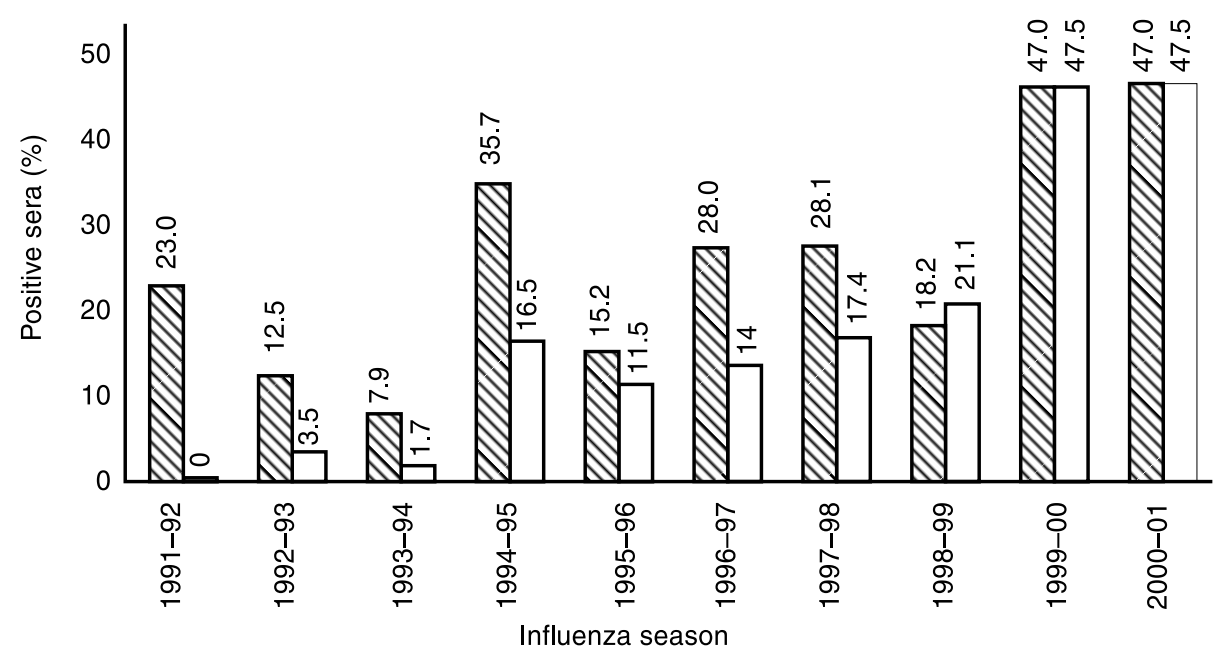

$\triangle$ Influenza A $\square$ Influenza B

Figure 3 Distribution of sera with $\mathrm{HI}$ antibody titre $\geq 160$ to influenza $A$ and $B$ during 19912001 (positive sera $=\mathrm{HI}$ antibody titre $\geq 160$ )

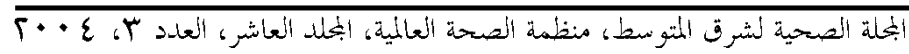


The season of maximum distribution of influenza was from November to April with a peak in February (Figure 1). The mild climate of the country might have influenced the incidence of influenza and severity of clinical symptoms. A correlation between influenza activity and climate has previously been suggested for other countries [8].

\section{Acknowledgement}

This work was supported by grant number 241/70/2 from the School Of Public Health and Institute of Public Health Research, Tehran University of Medical Sciences, Tehran, Islamic Republic of Iran.

\section{References}

1. Fields $B N$ et al., eds. Fields virology, 4th ed. Philadelphia, Lippincott Williams \& Wilkins, 2001:chapter 46.

2. Walsh JJ et al. Bronchotracheal response in human influenza type A, Asia strain, as studied by light and electron microscopic examination of bronchoscopic biopsies. Archives of internal medicine, 1961, 108:376-88.

3. Neuzil KM et al. The effect of influenza on hospitalizations, outpatient visits and courses of antibiotics in children. New England journal of medicine, 2000, 342: 225-31.

4. Neuzil KM et al. Influenza-associated morbidity and mortality in young and middle-aged women. Journal of the American Medical Association, 1999, 281:901-7.

5. Neuzil KM et al. Impact of influenza on acute cardiopulmonary hospitalizations in pregnant women. American journal of epidemiology, 1998, 148:1094-102.

6. White DO, Fenner FJ. Medical virology, 4th ed. San Diego, California, Academic Press, 1994:chapter 31.

7. Lennette $\mathrm{EH}$, Lennette DA, Lennette ET, eds. Diagnostic procedures for viral, rickettsial and chlamydial infections, 7th ed. Washington DC, American Public Health Association, 1995:chapter 1.
8. Kyriazopoulou $\mathrm{V}$ et al. Influenza surveillance in N. Greece during 1983-1993. Journal of infection, 1995, 30:167-71.

9. Influenza in the world: 1 October 199330 September 1994. Weekly epidemiological record, 1994, 69(50):373-7.

10. Recommended composition of influenza virus vaccines for use in the 1995-1996 season. Weekly epidemiological record, 1995, 70(8):53-6.

11. Recommended composition of influenza virus vaccines for use in the 1996-1997 season. Weekly epidemiological record, 1996, 71(8):57-64.

12. Recommended composition of influenza virus vaccines for use in the 1997-1998 season. Weekly epidemiological record, 1997, 72(9):57-64.

13. Influenza. Weekly epidemiological record, 1997, 72(39):293-6.

14. Update: influenza activity-United States, 1997-98 season. Morbidity and mortality weekly report, 1998, 47:196200.

15. From the Centers for Disease Control and Prevention. Isolation of avian influenza $A(H 5 N 1)$ viruses from humansHong Kong, May-December 1997. Journal of the American Medical Association, 1998, 279(4):263-4. 
16. Recommendation for the composition of influenza virus vaccines for use 1999. Weekly epidemiological record, 1998, 73(40):305-12.

17. Recommended composition of influenza virus vaccines for use in the 2001-2002 season. Weekly epidemiological record, 2001, 76(8):57-64.
18. Mokhtari-Azad T et al. Seroepidemiologic survey of influenza $C$ virus infection. The Journal of the Faculty of Medicine, Tehran University of Medical Sciences, 1999, 2:1-7.

\section{Intercountry meeting on Emerging Infectious Diseases (EID)}

The World Health Organization Regional Office for the Eastern Mediterranean convened the above-mentioned meeting in Beirut, Lebanon from 6 to 8 April 2004. The objectives of the meeting were:

- To promote communicable diseases surveillance and response activities for EID in the Eastern Mediterranean countries;

- To share experiences of Member States in combatting EID that occurred in 2003;

- To identify emerging health risks and develop plans of concerted efforts to control EID in Member States.

Directors of communicable disease programmes from all EMR Member States were invited to participate in the meeting. Representatives from nongovernmental organizations, UM organizations and other concerned partners, and staff members from $\mathrm{WHO} / \mathrm{HQ}$ were also invited to attend.

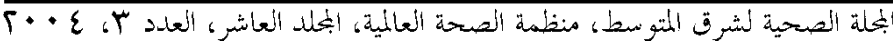

